See Article page $\mathrm{XXX}$.

\section{Commentary: Diamonds are forever: Not so for transcatheter aortic valve replacement}

\author{
Charles Laurin, MD, \\ Dimitri Kalavrouziotis, MD, FRCSC, and \\ Siamak Mohammadi, MD, FRCSC
}

Data on the long-term durability of transcatheter aortic valve replacement (TAVR) prostheses after 5 years are limited. With the expansion of TAVR indications across all surgical risk categories, it is expected that there will be an increase in the number of TAVR reinterventions. The optimal type of procedure (repeat TAVR vs surgical TAVR explant and surgical aortic valve replacement [SAVR]) among failed TAVR prostheses is undetermined.

In this issue of the Journal, Fukuhara and colleagues ${ }^{1}$ report the Michigan statewide experience with aortic prosthesis reintervention after TAVR. From 2012 to 2019, a total of 9694 patients underwent TAVR, and 87 patients $(0.90 \%)$ needed a reintervention on the TAVR prosthesis $(n=34$ were surgical TAVR explants, and $n=53$ underwent repeat TAVR). Not surprisingly, the authors report a significant increase in TAVR explant rates during the study period. Reintervention after TAVR was proportionally more frequent in self-expanding valves compared with balloon-expanding valves $(1.19 \%$ vs $0.70 \% ; P=.012)$, driven by a greater rate of surgical TAVR explant $(0.58 \%$ vs $0.19 \%$; $P=.001)$ among self-expanding valves. The rate of 30-day mortality was $15 \%$ in the TAVR explant group, although numbers were too small to elicit meaningful differences between patients with balloon- and selfexpanding valves.

\footnotetext{
From the Department of Cardiac Surgery, Quebec Heart and Lung Institute, Quebec City, Quebec, Canada.

Disclosures: The authors reported no conflicts of interest.

The Journal policy requires editors and reviewers to disclose conflicts of interest and to decline handling or reviewing manuscripts for which they may have a conflict of interest. The editors and reviewers of this article have no conflicts of interest.

Received for publication Sept 26, 2021; revisions received Sept 26, 2021; accepted for publication Sept 28, 2021.

Address for reprints: Siamak Mohammadi, MD, FRCSC, Department of Cardiac Surgery, Quebec Heart and Lung Institute, 2725 chemin Sainte-Foy, Quebec City, Quebec, Canada G1V 4G5 (E-mail: siamak.mohammadi@fmed.ulaval.ca).

J Thorac Cardiovasc Surg 2021; $\mathbf{\square}: 1-2$

$0022-5223 / \$ 36.00$

Copyright $(2021$ by The American Association for Thoracic Surgery

https://doi.org/10.1016/j.jtcvs.2021.09.050
}

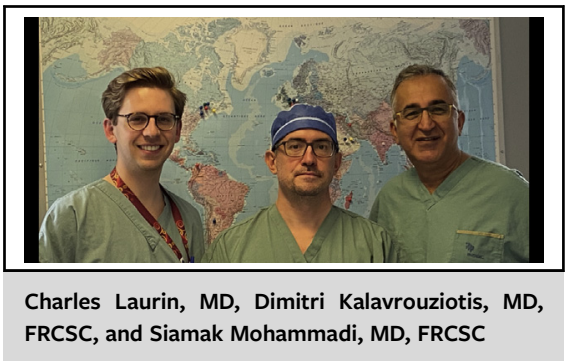

CENTRAL MESSAGE

The risks associated with TAVR

explant are not negligible and

compel the clinician to re-

evaluate prosthetic choice

(TAVR VS SAVR) for the initial

procedure.

There are 2 major take-home messages from the study by Fukuhara and colleagues. ${ }^{1}$ First, the risk of reintervention after TAVR is consistently reported to be less than $1 \%$, as published by Fukuhara and colleagues, ${ }^{1}$ and shown by others. ${ }^{2,3}$ As Fukuhara and colleagues ${ }^{1}$ acknowledge, these rates do not reflect the true incidence of structural valve deterioration and TAVR prosthesis durability, as patients undergoing reintervention (either repeat TAVR or surgical TAVR explant and SAVR) are highly selected. Stated differently, there is likely to be a sizeable cohort of patients with failing TAVR prostheses, in Michigan and other jurisdictions, who are not candidates for any reintervention. Second, approximately $40 \%$ of patients who underwent reintervention required a surgical TAVR explant and SAVR, mainly due to anatomical reasons (coronary anatomy and small TAVR prosthesis size). These patients had a $15 \%$ risk of operative mortality; this rate was similar to that previously reported for TAVR explant patients who were not candidates for repeat TAVR. ${ }^{3,4}$ These data are in noticeable contrast to the outcomes reported following reoperative SAVR among patients with failed surgical bioprosthetic valves, which can be performed in high-volume centers with an operative mortality of $<3 \%$, despite many patients requiring aortic annular enlargement. ${ }^{5,6}$

The analysis by Fukuhara and colleagues ${ }^{1}$ compels us to recognize the colossal importance of the index procedure that is chosen for the first AVR in the patient with aortic stenosis. This is especially valid for patients with low surgical risk, who are likely to outlive their prosthesis and require multiple reinterventions. The low-risk patient with aortic 
stenosis who is a candidate for both TAVR and SAVR can certainly be offered a low-risk TAVR with excellent early outcome, but they then become a high-risk patient for the inevitable reintervention if concomitant surgical procedures or a TAVR explant is required. Although early repeat TAVR outcomes are excellent in the study by Fukuhara and colleagues, ${ }^{1}$ long-term durability (after 1 year) of TAVR-inTAVR prostheses was not reported. This is highly relevant, as there are increasing reports of a greater risk of leaflet thrombosis and accelerated structural valve deterioration in TAVR-in-TAVR prostheses. ${ }^{7,8}$

Fukuhara and colleagues ${ }^{1}$ also report that patients with self-expanding prostheses requiring reintervention are more likely to undergo TAVR explant compared with patients with balloon-expanding prostheses. The data unfortunately are not granular enough to allow us to draw meaningful conclusions. Is the risk of coronary obstruction greater after repeat TAVR in self-expanding prosthesis due to their supra-annular position? Are self-expanding prostheses a marker for small aortic annuli precluding repeat TAVR? Do coronary access difficulties associated with self-expanding prostheses lead to a greater referral for TAVR explant and concomitant coronary artery bypass graft surgery? These questions ultimately remain unanswered.

The study by Fukuhara and colleagues ${ }^{1}$ provides a realworld glance into the fate that can be expected from
TAVR prostheses and ultimately leads us to re-evaluate the risk-benefit conversation with the patient with aortic stenosis regarding which index procedure (TAVR vs SAVR) is best, especially for those who are younger and have a low-risk profile.

\section{References}

1. Fukuhara S, Tanaka D, Brescia AA, Wai Sang SL, Grossman PM, Sukul D, et al. Aortic valve reintervention in patients with failing transcatheter aortic bioprostheses: a statewide experience. J Thorac Cardiovasc Surg. August 31, 2021 [Epub ahead of print].

2. Landes U, Webb JG, De Backer O, Sondergaard L, Abdel-Wahab M, Crusius L, et al. Repeat transcatheter aortic valve replacement for transcatheter prosthesis dysfunction. J Am Coll Cardiol. 2020;75:1882-93.

3. Ando T, Adegbala O, Aggarwal A, Afonso L, Takagi H, Grines CL, et al. Redo aortic valve intervention after transcatheter aortic valve replacement: analysis of the nationwide readmission database. Int J Cardiol. 2021;325:115-20.

4. Bapat VN, Zaid S, Fukuhara S, Saha S, Vitanova K, Kiefer P, et al. Surgical explantation after TAVR failure: mid-term outcomes from the EXPLANT-TAVR international registry. JACC Cardiovasc Interv. 2021;14:1978-91.

5. Sedeek AF, Greason KL, Sandhu GS, Dearani JA, Holmes DR Jr, Schaff HV. Transcatheter valve-in-valve vs. surgical replacement of failing stented aortic biological valves. Ann Thorac Surg. 2019;108:424-30.

6. Patel PM, Chiou E, Cao Y, Binongo J, Guyton RA, Leshnower B, et al. Isolated redo aortic valve replacement versus valve-in-valve transcatheter valve replacement. Ann Thorac Surg. 2021;112:539-45.

7. Deharo P, Bisson A, Herbert J, Lacour T, Etienne CS, Porto A, et al. Transcatheter valve-in-valve aortic valve replacement as an alternative to surgical re-replacement. J Am Coll Cardiol. 2020;76:489-99.

8. Rheude T, Pellegrini C, Stortecky S, Marwan M, Xhepa E, Ammon F, et al. Meta-analysis of bioprosthetic valve thrombosis after transcatheter aortic valve implantation. Am J Cardiol. 2021;138:92-9. 